\title{
FDI in the Former Soviet Periphery in Six Charts
}

\author{
Kalman Kalotay, United Nations Conference on Trade and Development (UNCTAD), Switzerland ${ }^{1}$
}

The FORMER SOVIET PERIPHERY is not a major interest for international business scholars. This is partly understandable as these are small and little known economies, hidden behind the center of the Soviet Union until its break-up in 1991. After gaining independence in 1991, these peripheral countries underwent a transition which proved to be more painful than in other parts of the formally centrally planned world. Nevertheless, their policy makers carried out major efforts towards economic reforms. Still, given their handicaps, their countries have attracted modest inflows of foreign investment, although fast growing over the past decade. Given this new-found dynamism, a partial rebalancing of attention of research in favor of these economies would be welcome.

\section{The context}

Until 1991, the Union of Soviet Socialist Republics, or generally called the Soviet Union, consisted of 15 constituent entities. For most outside observers this was a homogeneous block; very few (e.g., Carrère $d^{\prime}$ Encausse, 1978) noted at that time that the republics were not at all equal. The three Baltic societies ${ }^{2}$ considered themselves to be occupied and annexed territories, waiting for independence and a quick return the West, for this reason, this study uses the term "former Soviet Union and the Baltics." Of the remaining 12 republics, 6 were large or medium-sized. ${ }^{3}$ Already in the Soviet era, these economies belonged to the center or semi-center of the USSR With the exception of Belarus, they were rich in natural resources, and their resources were linked with the capital city of Moscow and the outside world with relatively good infrastructure. Belarus was less endowed by natural resources but had a strategic location on the Moscow-Warsaw-Berlin main route. These economies also concentrated the bulk of scientific and technological resources of the Soviet Union.

The remaining six republics (Armenia, Georgia, Kyrgyzstan, Moldova, Tajikistan and Turkmenistan) could be considered as periphery, located in remote landlocked areas, with the exception of Georgia, which had access to the Black Sea. And except for Turkmen natural gas and a gold mine in Kyrgyzstan, they were also poor in natural resources. They were located typically in the remote areas of the Soviet Union, and with the exception of Armenia, they concentrated a smaller proportion of scien- tific and technological capabilities. These were differences difficult to gauge because a centrally planned economy with a will to show some progress in all areas of the USSR located some white elephants in these republics, offering a facade of equally distributed development.

With the break-up of the Soviet Union in 1991, the differences between the center, the periphery and the Baltic States became evident. The latter groups made a very quick although painful transition to a market system, and rejoined the European Union (EU) in a historically brief time (by 2004). The six large- and medium-sized economies progressed more slowly. In terms of trade policy orientation, they opted for the creation of the own group, the Commonwealth of Independent States (CIS), of which five of them are full members (Ukraine is de facto participating in the CIS, although officially it is not a full member). Following the footsteps of the Baltic States, they also forged links with the World Trade Organization (WTO), although the exception of Ukraine (2008) and Russia (2012), they have not yet gained full membership. They engaged in cautious opening towards the EU: with the exception of Belarus (due to political problems), all of them ratified a Partnership and Cooperation Agreement (PCA) with that grouping.

The six small economies have experienced the most serious difficulties in transition. The typically suffered the most serious declines in output and employment as their productive capacities totally lost their raison d'être with the breakup of the Soviet economic system. Their inherited weaknesses have often been coupled by political instability, further hindering their economic and social progress. Georgia and Moldova have been victims of separatist movements, leading to a loss of control over parts of national territory. Armenia in turn was engaged in a territorial dispute with Azerbaijan. Kyrgyzstan has been marred by two uprisings $(2005,2010)$, the latter one coupled with ethnic violence. Tajikistan was devastated by a protracted civil war (1992-1997), while between 1991 and 2006 Turkmenistan operated a single-party closed dictatorship. All these developments meant hardship for local populations and a halt to economic development.

These economies attempted to mitigate their handicaps partly by international integration efforts. This explains why four out of the six small economies are already members of the WTO. Only Tajikistan remains an observer and isolated Turkmenistan has no official relations with WTO. These smaller economies, with the exception of Georgia, are also mem- 
bers of the $\mathrm{CIS}^{4}$ and have, again with the exception of Turkmenistan, a PCA with the EU. Moreover, two of them, Georgia and Moldova are currently negotiating Deep and Comprehensive Free Trade Agreements with the EU, locking their regulatory environment with that of the EU. ${ }^{5}$

\section{What attracts investment into small former Soviet republics}

Despite the handicaps described above, investors could find certain business opportunities in the former Soviet periphery, especially related to competitive labor costs. In 2011, the population of the small economies was about 30 million, i.e. about 10\% of the former Soviet Union, if the Baltic States are included (the share of big and mediumsized economies was $88 \%$ and that of the Baltic countries 2\%) (Figure 1). At the same time, the small former Soviet economies accounted for only $4 \%$ of the GDP in purchasing power parity (PPP) (Figure 2). In fact, their share was slightly lower than that of the Baltics, whose population is almost five times less. In other terms, their average GDP per capita (in PPP) was about $\$ 4,300$, three times less than in the large and mediumsized States (about $\$ 13,000$ ) and almost five times less than in the Baltics (about $\$ 21,000$ ). This is particularly surprising because it means that in term of standard of living, the big and medium-sized countries are now closer to the Baltics than to the former Soviet periphery.

Figure 1. Population of the former Soviet Union and the Baltic States by country group, 2011 (Per cent)



Source: Author's calculation, based on data from the United Nations Economic Commission for Europe (UNECE) Statistical Database.
Figure 2. GDP of the former Soviet Union and the Baltic States by country group, 2011 (Per cent)

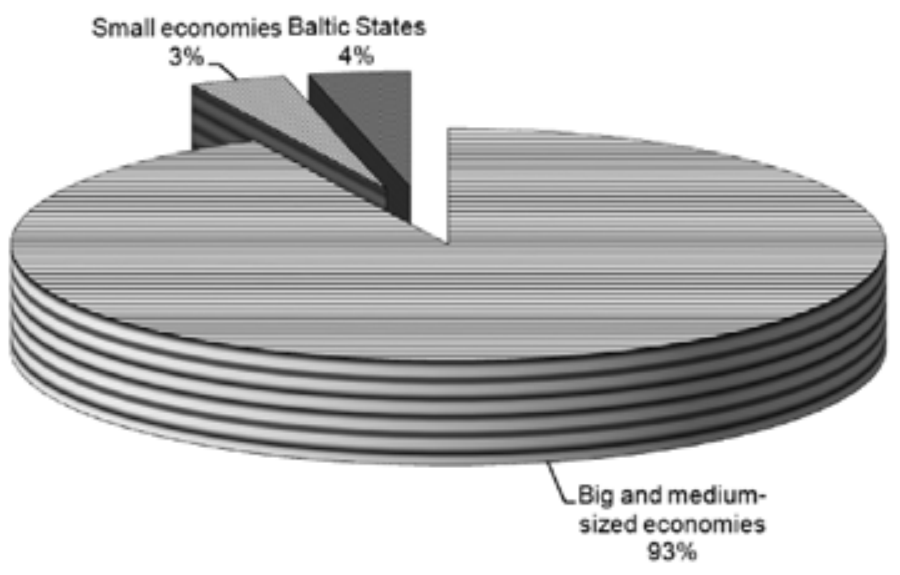

Source: Author's calculation, based on data from the UNECE Statistical Database.

A look at the level of reforms indicates that the former Soviet periphery has made in general a larger effort towards economic reforms than the large and medium-sized economies, although it lags significantly behind the Baltic States. However generalizations are difficult because the first two groups are very diverse. Among the small economies, Georgia, and to a lesser degree, Armenia and Kyrgyzstan are reform-driven societies, while Turkmenistan is one of the most "repressed" economies of the world. ${ }^{6}$

Progress with reforms is best compared with the Baltic States as the latter, too, used to be ruled by the Soviet Union, although their initial conditions for transition, especially in terms of human resources and institutions was more favorable than those of the Soviet periphery. However it also seems that since the early 1990s, those differences continued to increase. In terms of the Index of Economic Freedom of the Heritage Foundation, in 2013 the Baltics consisted in their majority "mostly free" economies, the former Soviet periphery in its majority "mostly unfree" and the large and medium-sized economies in their majority "repressed" economies. These averages naturally cover outliers. Among the large economies, Russia, the largest, is already "mostly unfree". Among the small economies, Georgia is "mostly" and Armenia "moderately free". If the ranking of the Baltic States is taken as "1", the average of the former Soviet periphery is about 3 and that of the large and medium-sized economies is "4" (Figure 3). The post-Soviet universe is also sharply divided in terms of "investment freedom". In the majority of cases, the degree of freedom fluctuates between 20 and 55\%, but reaches of exceeds 75\% in the three Baltic States, Armenia and Georgia (both small economies), while it is $0 \%$ in Turkmenistan (small economy) and Uzbekistan. 
Figure 3. Institutional distance of the former Soviet Union from the Baltic States by country group, latest year available

(Baltic States $=1$ )

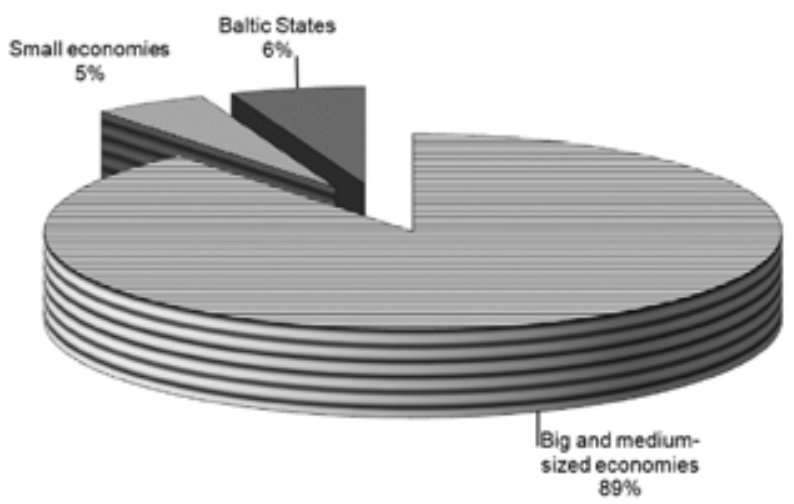

Source: Author's calculation, based on data from Heritage Foundation, Transparency International and World Bank.

In the former Soviet Union and the Baltic States there is some relationship between the level of investment freedom and FDI per capita, and the trendline is rising (more investment freedom in general goes hand in hand with higher FDI per capita) indicating the possibility that the former can influence the latter (Figure 4). However the R square is not very strong (27\%), suggesting that other factors such as the general regulatory environment and natural resource endowments also play and important role. Of the six small former Soviet republics, five are below the trendline, i.e. they have attracted less FDI than their investment freedom would suggest. The only exception is natural-gas-rich Turkmenistan. Among the six large and medium-sized economies, only two (Kazakhstan and Russia) are above the trendline. They have

Figure 4. Relationship between investment freedom and FDI stock per capita in the former Soviet Union and the Baltic States, 2011 (Per cent and US\$)

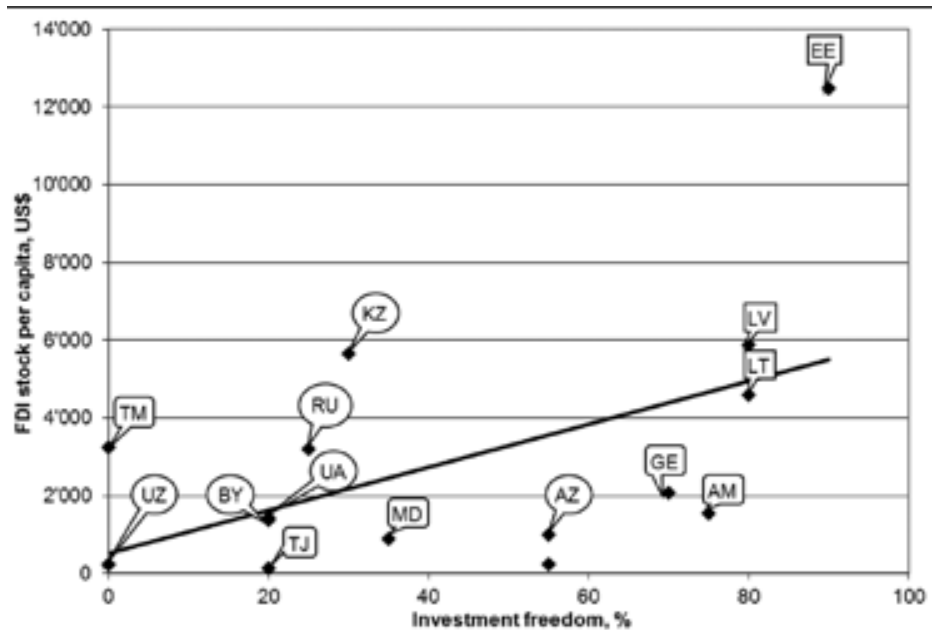

Source: Author's calculation, based on data from Heritage Foundation and UNCTAD's Foreign Direct Investment/Transnational Corporations (FDI/TNC) database. attracted larger amounts of FDI thanks to their broad investment possibilities than their openness would suggest. Among the Baltic States, two are slightly below the trendline, while Estonia has attracted more than twice as much FDI as its openness alone - although impressive would suggest.

In terms of fight for transparency as measured by the 2012 Corruption Perceptions Index of Transparency International, the distance of both the small and the large and medium-sized former Soviet economies from the Baltic States is large. The average ranking of the Baltics taken as 1, their values are 2.7 and 3.1, respectively (Figure 3). Only Georgia's global rank is comparable with those of the Baltic States; in the rest of the former Soviet Union, with the exception of Moldova (94 $\left.{ }^{\text {th }}\right)$, the rank is well beyond 100. Finally, it is worth applying the Ease of Doing Business Rank of 2013 of the World Bank, even if it is more targeted towards locally owned small business than foreign investors, and always faces the difficulty of fully measuring the efficiency of implementation of laws. In this ranking again the Baltic States are in general the best ranked, with the exception of Georgia, which surpasses all of them with a global $9^{\text {th }}$ rank. Also noticeably the global rank of Armenia is not far from that of the Baltic States. On average, if the Baltics rank is "1", that of the small economies is about " 3 " and of the large and medium-sized economies is "4" (Figure 3).

\section{Inbound and outbound FDI}

As the former Soviet periphery has overcome only part of its handicap (small size, low GDP, remote location) through regulatory reforms, its inward FDI has been modest in global comparison, although fast growing over the past decades, and has been moderately affected the crisis that started in 2008. By the end of 2011, its inward FDI stock reached $\$ 36$ billion, i.e., $0.18 \%$ of the world total (Figure 5). Ten years before, in

Figure 5. Share of the small former Soviet republics in world FDI inward and outward stocks, 1993-2011 (Per cent)

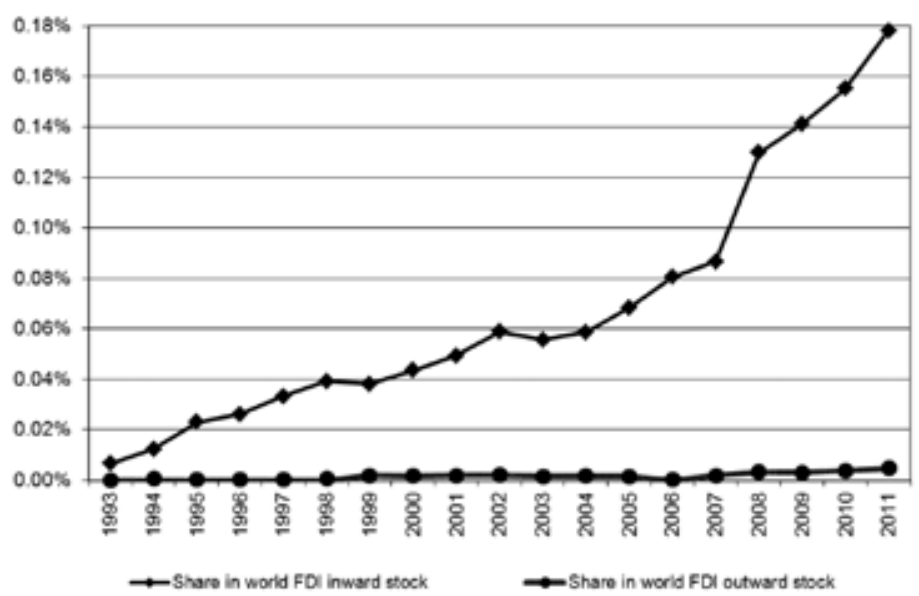

Source: Author's calculation, based on data from the UNCTAD's FDI/TNC database. 
20001, it amounted to $\$ 4$ billion only, i.e. $0.05 \%$ of world total. To put it into a post-Soviet perspective, the share of these small economies reached $5 \%$ of the total of the 15 countries that constituted the former USSR in 1991 (Figure 6). This share is only half of their share in population but higher than their share in GDP. Therefore there is an untapped potential in per capita FDI but not in per GDP FDI. It is notable, although it is mostly expected, that the share of the Baltics in inbound FDI stock (6\%) exceeds both their share in population and their share in GDP.

Figure 6. Inward FDI stock of the former Soviet Union and the Baltic States by country group, 2011 (Per cent)



Source: Author's calculation, based on data from the UNCTAD's FDI/TNC database.

In the area of outward FDI, the former Soviet periphery is very weak, showing the lack of local firms and entrepreneurial skills for effectively carrying out such projects. In 2011, the combined outward FDI stock of the grouping remained under $\$ 1$ billion, meaning that the inward stock was 37 times higher than the outward one, which is a striking unbalance. In the post-Soviet context, that accounts for a mere 0.2\% (which cannot even be shown in a pie chart due to its minuscule size), compared with close to $2 \%$ for the Baltics and close to $98 \%$ for the large of medium-sized economies (of which Russia alone accounted for 89\%).

\section{Investment opportunities}

The fast growth of inward FDI shows that despite all the problems the former Soviet periphery possesses certain attractiveness for foreign investors, going beyond the obligatory natural resources (which in this case means the Turkmen natural gas, the Kyrgyz gold, and hydroelectric potential in the Central Asian mountains). Despite small size and low income, these countries have attracted certain market seeking investors, especially in telecommunications, in which the Russian giants (MTS, Vimpelcom, Megafon) have been joined by Orange, TeliaSonera and Turkcell, in retail, in oil and gas distribution, building materials, food and beverages, and in banking. Success has been moderate in terms of efficiency seeking projects despite the existence of free economic zones in various countries. Moldova, the economy closest located to the EU has attracted automotive projects (DräxImaier, Lear, Leoni).

In all of these areas, there remain important untapped business opportunities. There are also other industries in which already existing comparative or competitive advantages could lead to more investment, such as agribusiness, ICT and tourism. The underdeveloped nature of infrastructure would also offer business opportunities, especially in the form of public-private partnerships.

So far the inflows of FDI in the former Soviet periphery have been attracted from various parts of the world, including the EU, North America and to some degree Asia. An especially important role has been played by Russian firms which are often taking advantage of historical and cultural links (Kuznetsov, 2012). The importance of these links goes beyond what the numbers would suggest - in any case, an important part of Russian investment is indirect FDI (Kalotay, 2012), i.e., registered as projects from third countries such as Cyprus - as Russian investors often follow very long-term strategic objectives going beyond shortterm profit considerations. One recent case is Russian firms' long-term involvement in the development of hydroelectric power is Kyrgyzstan (Reuters, 2012).

Another specificity of at least some FDI in the former Soviet periphery is its potential link with official development assistance (ODA). This is a current phenomenon in relatively weak host economies in which the persistent lack of business opportunities cannot be overcome without the involvement of other, mostly public funding, especially in infrastructure development, which is often the most serious bottleneck to investment. This trend of mixing FDI, loans and ODA in single packages then can be reinforced by certain home/donor countries such as China and Russia which make those packages integral part of their international economic diplomacy. In the former Soviet periphery, a recent example is the Sangtuda 1 Hydroelectric Power Plant in Tajikistan, in which the majority participation of the Russian and Tajik Governments is complemented by Russian corporate investment by FGC UES and Inter RAO UES?

To conclude the specificities of current and potential FDI, it is evident that the small former Soviet republics need strong investment promotion efforts if they wish to overcome their handicaps and convince potential foreign investors first to put them on the map and then choose them for concrete projects. This requires image building - already a difficult task given the troubled past of some of these countries - then forceful and professional targeting of potential investors, followed by good investor services, especially services related to establishment of firms and aftercare, as well as policy advocacy. Those economies such as Georgia and Armenia, which have good Doing Business rankings can use them as leverage in their campaigns with investors. With the exception of Turkmenistan, the former Soviet periphery has its own investment promotion agencies (in Armenia and Moldova an agency com- 
bining with export promotion). All the six have some forms of export processing zones providing incentives and other advantages to foreign investors. However it is less clear to what degree the investment promotion agencies fulfill their functions in a professional manner. In many cases, they have to compete for scarce human and financial resources, and their success depends on the decision of political forces ultimately deciding their distribution.

\section{In lieu of conclusion: what about IB research?}

The former Soviet periphery is far from being a top interest for international business scholars. In leading journals very few studies have focused so far on FDI or other issues of international business the Soviet periphery (such as Kaynak et al., 2006, comparing FDI in Georgia and Kyrgyzstan). In some other cases, a small former Soviet republic is compared with a large one (for example in Luthans \& Ibrayeva, 2006, comparing entrepreneurship in Kazakhstan and Kyrgyzstan). It is more common that certain small former Soviet republics are part of a broader sample of countries analyzed (such as Gillespie et al., 1999, looking at diaspora investment in various countries including Armenia). The dates of these studies indicate that such interest is not taking off recently either, perhaps dues to the protracted economic difficulties of the former Soviet periphery. Having these considerations in mind, it is still surprising to see the enormous gap of interest compared with Russia, in particular, which under the umbrella of BRICs has seen international research interest explode recently, and especially the emerging market that has been the most lavishly covered: China. This study of course does not argue that all academics should switch from China or Russia to say Kyrgyzstan or Georgia but definitively some degree of rebalancing the neglect would be welcome.

\section{References}

Carrère d'Encausse, H. 1978. L'Empire éclaté. Paris: Flammarion.

Gillespie, K., Riddle, L., Sayre, E. \& Sturges, D. 1999. Diaspora Interest in Homeland Investment. Journal of International Business Studies, 30(3): 623-634.

Kalotay, K. 2012. Indirect FDI. The Journal of World Investment \& Trade, 13(4): 542-555.

Kaynak, E., Yalcin, S., \& Tatoglu, E. 2006. A Comparative Study of Foreign Direct Investment Activities in Georgia and Kyrgyz Republic. Multinational Business Review, 14(3): 29-52.

Kuznetsov, A. 2012. Monitoring Mutual Investments in CIS Countries. In Eurasian Integration Yearbook 2012: 129-149. Almaty: Eurasian Development Bank.

Luthans, F., \& Ibrayeva, E. S. 2006. Entrepreneurial self-efficacy in Central Asian transition economies: quantitative and qualitative analyses. Journal of International Business Studies, 37(1): 92-110.
Reuters, 2012. Russia firms footprint in Kyrgyzstan with hydro project. Reuters, 27 October, http://uk.reuters.com/article/2012/10/27/ uk-kyrgyzstan-rushydro-idUKBRE89Q08120121027.

\section{Endnotes}

1. The views are those of the author and do not necessarily reflect the opinion of the United Nations.

2. Estonia, Latvia and Lithuania.

3. Azerbaijan, Belarus, Kazakhstan, Russia, Ukraine and Uzbekistan.

4. Turkmenistan's status is called "unofficial associate member".

5. Additionally, Moldova is member, together with the economies of the Western Balkans, of the Central European Free Trade Agreement.

6. According to Heritage Foundation, a "repressed" economy has its private sector activities seriously curtailed by laws and regulations.

7. The political, social and ecological controversy surrounding this case would deserve a separate study.

Kalman Kalotay is Economic Affairs Officer at the Division on Investment and Enterprise of the United Nations Conference on Trade and Development (UNCTAD). Currently he works in the group preparing UNCTAD's Investment Policy Reviews. Between 1996 and 2009, he was part of UNCTAD's World Investment Report team. He also served as associate (1996-2003) and deputy editor (2003-2004) of UNCTAD's Transnational Corporations journal. He holds a Ph.D. in International Economics from Corvinus University, Hungary. 